\title{
Prevalence of Abuse Among Young Children with Rib Fractures: A Systematic Review
}

\author{
Christine Weirich Paine, MPH ${ }^{1}$, Oludolapo Fakeye, MA $^{1}$, Cindy W. Christian, MD $^{1,3}$, and \\ Joanne N. Wood, MD, MSHP1,2,3 \\ ${ }^{1}$ Division of General Pediatrics and PolicyLab, The Children's Hospital of Philadelphia, \\ Philadelphia, Pennsylvania \\ ${ }^{2}$ Leonard Davis Institute of Health Economics, Perelman School of Medicine at the University of \\ Pennsylvania, Philadelphia, Pennsylvania \\ ${ }^{3}$ Department of Pediatrics, Perelman School of Medicine at the University of Pennsylvania, \\ Philadelphia, Pennsylvania
}

\begin{abstract}
Objectives-We aimed to estimate the prevalence of abuse in young children presenting with rib fractures and to identify demographic, injury, and presentation-related characteristics that affect the probability that rib fractures are secondary to abuse.

Methods-We searched PubMed/MEDLINE and CINAHL databases for articles published in English between January 1, 1990 and June 30, 2014 on rib fracture etiology in children $\leq 5$ years old. Two reviewers independently extracted predefined data elements and assigned quality ratings to included studies. Study-specific abuse prevalences and the sensitivities, specificities, and positive and negative likelihood ratios of patients' demographic and clinical characteristics for abuse were calculated with $95 \%$ confidence intervals.
\end{abstract}

Results-Data for 1,396 children $\leq 48$ months old with rib fractures were abstracted from 10 articles. Among infants < 12 months old, abuse prevalence ranged from $67 \%$ to $84 \%$, whereas children 12-23 months old and 24-35 months old had study-specific abuse prevalences of 29\% and $28 \%$ respectively. Age $<12$ months was the only characteristic significantly associated with increased likelihood of abuse across multiple studies. Rib fracture location was not associated with likelihood of abuse. The retrospective design of the included studies and variations in ascertainment of cases, inclusion/exclusion criteria, and child abuse assessments prevented further meta-analysis.

Conclusions-Abuse is the most common cause of rib fractures in infants $<12$ months old. Prospective studies with standardized methods are needed to improve accuracy in determining abuse prevalence among children with rib fractures and characteristics associated with abusive rib fractures.

Corresponding Author: Christine Weirich Paine, MPH, The Children's Hospital of Philadelphia, 3535 Market Street, Room 1505, Philadelphia, PA 19104, painec@email.chop.edu, Phone: 267-426-0369, Fax: 267-426-0380.

Conflicts of Interest

The authors do not have conflicts of interest to disclose. 


\section{Keywords}

child abuse; child maltreatment; rib fracture; accident; trauma

\section{Introduction}

Rib fractures, particularly posteromedial rib fractures, in young children are reported to have high specificity for child abuse. ${ }^{1,2}$ Although uncommon, rib fractures in this age group have also been attributed to accidental trauma mechanisms, including motor vehicle crashes (MVCs), accidental household trauma, and birth trauma. ${ }^{3}$ In addition, rib fractures have been documented in the absence of a history of significant trauma in children with a variety of bone diseases, such as osteopathy of prematurity and osteogenesis imperfecta. ${ }^{3-5}$ Determining the etiology of rib fractures in young children can be challenging for the clinician.

Associations between specific rib fracture locations or features and likelihood of abuse have been widely reported in the literature. In particular, posterior and posteromedial rib fractures have been reported to have a higher specificity for abuse than rib fractures in other locations. 1,2,6-15 The articles commonly cited to support this association are, however, at least 25 years old and/or rely on data from case series studies using postmortem examinations of abused children and do not compare the characteristics of rib fractures from abuse to the characteristics of rib fractures from accidental trauma. ${ }^{7-15}$ There is reason to suspect that there may be changes in the type and number of rib fractures attributed to abuse and accidental injury mechanisms over time as there have been advances in the evaluation and diagnosis of child abuse over the past 25 years. Child abuse is a relatively new field; many pediatric centers did not establish child abuse programs until after $1990 .{ }^{16-18}$ Furthermore, in 2011, recommendations from the American College of Radiology and the American Academy of Pediatrics changed to include oblique rib views as part of the standard skeletal imaging in cases of suspected physical abuse in young children. ${ }^{19-21}$ Hence, comprehensive examination of recent literature is needed to better understand the characteristics of rib fractures associated with abuse versus other etiologies.

Therefore, we performed a systematic review of contemporary research articles to estimate the prevalence of abuse in young children presenting with rib fractures and to identify demographic, injury, and presentation-related characteristics that affect the probability that rib fractures are secondary to abuse. We included children up to age 5 years in our review, acknowledging that, although the majority of abusive fractures occur in infants and young toddlers, abusive fractures have also been reported in preschool age children., ${ }^{52-26}$ In order to provide a more complete understanding of the prevalence of abuse in different subpopulations of children with rib fractures, we present the proportions of children with rib fractures diagnosed with abuse in each study as well as details of the study population and study methods. 


\section{Materials and Methods}

\section{Search Strategy}

As previously described by our research group, a systematic review of the literature on abuse in children with fractures was performed using a pre-specified protocol with inclusion/ exclusion criteria (available upon request). The present manuscript includes the subset of articles providing information on rib fractures (Figure 1). Using the table of search terms provided in Supplemental Digital Content 1, we performed a search for studies published in English between January 1990 and June 2014 in the PubMed/MEDLINE and CINAHL databases. Search terms related to both accidental trauma and abuse were included to avoid bias toward studies focused on abusive rib fractures. Additional studies were identified by reviewing reference lists of articles identified through the database searches. We selected a cutoff date of 1990, as there have been significant changes in the field of child abuse pediatrics over the past 25 years, and the evaluation and diagnostic practices have improved. $16-18$

\section{Study Selection}

We included randomized controlled trials (RCT), prospective non-RCT studies, and retrospective data analyses, but excluded reviews, surveys, editorials, and textbooks. Studies were included if subjects were $\leq 5$ years old or if the data for the subset of children $\leq 5$ years old could be extracted. Studies reporting data on fewer than 10 children $\leq 5$ years old with rib fractures were excluded, as such a small sample size would provide unstable studyspecific estimates. Methodologically weak studies, characterized by significant bias in selection of subjects (e.g. if a study required that a child be abused in order to be included in the study or only included cases evaluated by the author for medical legal review) or that did not allow for extraction of adequate data were excluded. We excluded studies that a priori included only children with rib fractures from either accidental mechanisms or abusive mechanisms, as these studies do not provide information on the prevalence of abuse or allow for calculation of the study-specific sensitivity and specificity of characteristics for abuse. Studies were not excluded if rib fractures from both abusive and accidental mechanisms could have met inclusion criteria, even if all of the included cases were from abuse. Exclusively post-mortem studies were also excluded as they do not provide information on the prevalence of abuse in the general population of children presenting for care. Study titles and abstracts were screened by one of five reviewers (XX, XX, XX, XX, or XX), and nonrelevant studies were eliminated (Figure 1). Two reviewers (XX and XX, XX, XX, or XX) assessed the full manuscripts of relevant studies for eligibility in an unblinded, standardized manner, with disagreements resolved by consensus.

\section{Data Extraction, Assessment of Methodological Quality, and Analysis}

Two reviewers (XX and XX or XX) independently extracted the following data from each included study using a standardized form: a) study population characteristics (subject ages, type(s) of fractures, location of study, and dates of study), b) inclusion and exclusion criteria for subjects, and c) number of fractures attributed to abuse versus accidental mechanisms or medical disease in the overall study population as well as study subpopulations. The two reviewers independently rated the overall study methodology using the scale from A-D 
(Table 1). The reviewers also rated the methodology that each study employed to determine whether or not an injury was caused by abuse. The scale applied was adapted from one published by Maguire and colleagues which assigns the highest rank (1) to studies requiring that abuse be either confirmed at a child abuse case conference or civil or criminal court proceedings, admitted by a perpetrator, or witnessed. ${ }^{27}$ The lowest rank (5) was given to studies providing no stated criteria for categorizing cases as suspected abuse. Finally, the two reviewers evaluated risk of bias by assessing whether a) the study population was representative of the general population of children $\leq 5$ years old with rib fractures (e.g., Is the study population a subgroup of the children that met inclusion criteria? Did the study include all young children with rib fractures, or only the subgroup evaluated for abuse, prematurity, etc.?) and b) the selection criteria used were clearly presented in the manuscript. Disagreements between reviewers were resolved through discussion and consensus.

For each cross-sectional and cohort study, the prevalence of abuse in young children presenting with rib fractures was calculated with $95 \%$ confidence intervals (CIs) from the reported data. The study-specific sensitivity, specificity, positive likelihood ratio, and negative likelihood ratio of subjects' demographic and clinical characteristics for abuse were also calculated with $95 \%$ CIs where possible. The $95 \%$ CIs for the likelihood ratios were computed using the formulae described by Simel and colleagues. ${ }^{28}$ All other analyses were performed using Stata 12 (StataCorp, College Station, TX).

\section{Results}

\section{Description of Studies}

The database search and reference review identified 7,599 non-duplicate citations, of which 395 were deemed relevant after review of the titles and abstracts. Ten studies on rib fractures met inclusion criteria for this review. ${ }^{3-5,22,29-34}$ Data for 1,396 children aged 0-48 months with rib fractures were abstracted from the 10 articles (Table 2). None of the studies included data on children aged 49-59 months with rib fractures. All of the included articles presented data from retrospective studies. Six articles judged to have clearly defined data sources and criteria received a methodology rating of $C^{3,22,30-33}$ and the remaining articles received a rating of D. ${ }^{4,5,29,34}$ Abuse determination methodology varied among studies. A single study required that the determination of abuse be made by the site's Child Protection Unit and Suspected Abuse and Neglect Team, which included representation from the hospital child abuse protection pediatrician and social worker as well as from the local child welfare and police agencies. This study was assigned a methodology rating of 1 for child abuse determination. ${ }^{4}$ Three articles reported the specific case-based criteria used to make a determination of child abuse and received a rating of $3 a$ or $3 b^{3,31,33}$ The remaining six received abuse determination ratings of 4 or $5.5,22,29,30,32,34$ Leventhal et al. used ICD-9 Ecodes to identify young children with abusive rib fractures, an ascertainment method shown to have high specificity for abuse. ${ }^{22,35,36}$ Nonetheless, the abuse diagnosis criteria remain unclear with this method; thus, the study received a rating of 4 .

All 10 studies included infants, but the upper age limit ranged from 12 to 48 months among the studies. There were variations in the inclusion and exclusion criteria used in subject 
selection, particularly with respect to possible etiologies of the rib fractures. Five studies included children with rib fractures from any possible etiology, ${ }^{3-5,22,29}$ although one of these studies excluded birth-related hospitalizations. ${ }^{22}$ Two studies excluded children with rib fractures caused by bone disease. ${ }^{31,33}$ Two case-control studies excluded cases if a clear determination of abusive or accidental trauma could not be made; ${ }^{33,34}$ one of these only included cases evaluated in the emergency department or inpatient setting. ${ }^{33}$ In addition, the study by Lucas-Herald and colleagues focused solely on infants born at $<37$ weeks gestation and excluded patients with rib fractures attributed to thoracotomy surgery. ${ }^{32} \mathrm{We}$ chose not to perform a meta-analysis due to the heterogeneity of study populations and methodologies.

\section{Abuse prevalence in young children with rib fractures}

The study-specific prevalence of abuse for the two studies providing data on children $<36$ months of age with rib fractures from any reported etiology ranged from $61 \%$ to $82 \%$ (Figure 2A). ${ }^{5,22}$ Among studies reporting data on children $<36$ months of age with rib fractures not attributed to underlying bone disease, study-specific abuse prevalence ranged between $64 \%$ and $100 \%$ (Figure 2B). ${ }^{30,31}$

Among children < 24 months of age with rib fractures from any reported etiology, the prevalence of abuse across three studies ranged from $34 \%$ to $83 \%$. $^{4,22,29}$ Among studies reporting data on children $<24$ months of age with rib fractures not attributed to MVC, study-specific prevalence of abuse ranged from $36 \%$ to $94 \% .{ }^{4,29}$ Further restriction of study cohorts to children $<24$ months of age with rib fractures not attributed to bone disease or MVCs produced abuse prevalence estimates ranging from $67 \%$ to $100 \%{ }^{4,29}$

Focusing on data specifically for infants $<12$ month of age resulted in a prevalence of abuse of $67 \%$ to $82 \%$ if MVCs and bone disease were included, ${ }^{3,22}$ and a point prevalence estimate of $91 \%$ if MVCs and bone disease were excluded. ${ }^{3}$ In a study of 26 ex-preterm infants $<12$ months old with rib fractures, Lucas-Herald and colleagues found that the majority was noted to have rib fractures during their birth hospitalization and 18 had osteopathy of prematurity. ${ }^{32}$ Among the seven infants with rib fractures diagnosed post-discharge, four $(57 \%)$ were suspected to be due to abuse. These results are not generalizable to nonpremature infants.

The single study that allowed for separate analyses of the data for children 12-23 months old and children 24-35 months old produced estimates of $29 \%$ and $28 \%$ respectively for the abuse prevalences in these age groups. ${ }^{22}$

\section{Demographic characteristics associated with abuse determination}

Three studies provided data on children with rib fractures that allowed for analysis of the association between demographic characteristics and likelihood of abuse. Age $<18$ months old, particularly $<12$ months old, was associated with increased likelihood of abuse in 3 studies (Table 3). ${ }^{22,33,34}$ Male gender was not associated with the likelihood of abuse in the single study examining this association. ${ }^{33}$ 


\section{Rib fracture characteristics associated with abuse determination}

Four studies included data on characteristics of rib fractures in children that permitted analysis of associations with likelihood of abuse (Table 3). In the study by Bulloch and colleagues, the presence of posterior rib fractures was not associated with the likelihood of abuse. ${ }^{3}$ Cadzow and Armstrong reported that anterior rib fractures were associated with increased likelihood of abuse, lateral rib fractures were associated with decreased likelihood of abuse, and posterior rib fractures were not significantly associated with likelihood of abuse. ${ }^{4}$ Associations in the study by Cadzow and Armstrong, however, were based on the number of individual fractures in each location rather than the number of children with rib fractures in those locations. This approach may have given a few children with many abusive anterior rib fractures more weight in the likelihood calculations. Therefore, we did not include these results in Table 3.

In a study by Strouse et al of 35 children with rib fractures, 3 of the 4 first-rib fractures identified among the main study cohort were attributed to abuse, but the association of a first rib fracture with abuse did not reach statitistical significance. ${ }^{29}$ Darling and colleagues found that healing rib fractures, bilateral rib fractures, and a greater number of ribs fractures (5.55 \pm 4.24 vs. $3.11 \pm 2.52, \mathrm{p}=0.025)$ were associated with increased likelihood of abuse, ${ }^{33}$ but no other studies examined these associations. In the same study, only abused children had concurrent acute and healing rib fractures, but this finding did not reach statistical significance. ${ }^{33}$

\section{Presence of additional injuries and abuse determination}

Cadzow and Armstrong did not find an association between the presence of additional injuries and the likelihood of abuse. ${ }^{4}$ Darling and colleagues found that extrathoracic, nonskull fractures and retinal hemorrhages were associated with increased likelihood of abuse, but intrathoracic injuries were associated with decreased likelihood of abuse. ${ }^{33}$ The following were not significantly associated with likelihood of abuse in this study when present in addition to rib fractures: non-rib thoracic cage (clavicle, scapula, sternum, and thoracic spine) injuries, intra-abdominal injuries, intracranial injuries, and skull fractures. ${ }^{33}$

\section{Discussion}

We identified 10 retrospective studies providing data on prevalence and/or characteristics associated with abuse among young children with rib fractures. The prevalence of suspected or confirmed abuse among children $<36$ months old presenting with rib fractures varied from $34 \%$ to $100 \%$ across the studies, reflecting heterogeneity of their study populations and methodologies. Excluding MVC and bone pathology as fracture etiologies produced abuse prevalence rates of $67 \%-100 \%$ in children $<24$ months old and $91 \%$ in children $<12$ months old, demonstrating the high prevalence of abuse in young children with rib fractures. Our estimates of the abuse prevalence for young children presenting with rib fractures are consistent with the 66\% abuse prevalence for children 0-48 months old with rib fractures reported in the 2013 systematic review by Kemp and colleagues, even though the inclusion criteria differ slightly. 37,38 
Despite the widely reported specificity of posterior rib fractures for abuse, we did not find evidence supporting an increased likelihood of abuse in children with posterior rib fractures as compared to rib fractures in other locations, possibly because of the small sample sizes and low power of studies examining this association. In fact, our review did not identify any recent studies supporting an association between a specific rib fracture location and likelihood of abuse. Based on their systematic review, Kemp et al. reported an increased likelihood of abuse in anterior rib fractures and decreased likelihood of abuse in lateral rib fractures, but a variable association of posterior rib fractures with the likelihood of abuse in 3 studies reviewed for their publication. ${ }^{3-5,37}$ We did not include two of the three studies cited by Kemp et al. in our formal analysis of the association of rib fracture location with the likelihood of abuse, because the data presented in these two studies did not meet our study criteria. One study included children up to age 15 years in their analysis of rib fracture location. ${ }^{5}$ Both studies presented data for the number of rib fractures in each location and not the number of children with rib fractures in each location. ${ }^{4,5}$ As stated earlier, this method is problematic because abused children with multiple rib fractures in a specific location may inflate the association between fractures in that location and abuse. A 2012 case series study describing 3 abused infants with first rib fractures discovered on imaging recommends that clinicians suspect child abuse in infants with first rib fractures. ${ }^{39}$ Although our review did not identify sufficient data to demonstrate a higher specificity of abuse for a fracture of the first rib compared to a fracture of other ribs, the high prevalence of abuse in infants with rib fractures should be enough to cause the clinician to suspect abuse.

Although rib fracture location was not identified as a predictor of abuse in our review, the presence of bilateral rib fractures was shown to be associated with abuse. This association, however, was noted in only one study by Darling et al. and will need to be confirmed. ${ }^{33}$ Additionally, Darling et al. found that healing rib fractures were identified exclusively in abused children. ${ }^{33} \mathrm{Rib}$ fractures in multiple stages of healing were also only identified in the abused group, but this association did not reach statistical significance, possibly due to the small sample size. ${ }^{33}$ Surprisingly, Darling et al. did not find an association between rib fractures with intracranial injury and abuse, ${ }^{33}$ and Cadzow and Armstrong did not find an association between rib fractures with additional injuries and abuse. ${ }^{4}$ Further examination shows, however, that the majority of accidental rib fractures in these studies were due to high velocity, significant trauma such as MVCs and falls from significant heights. These are mechanisms that can result in multisystem trauma and are unlikely to be confused with child abuse.

This review has several limitations. First, the included studies were retrospective and, as a result, subjects were not clinically evaluated in a consistent manner (e.g., various numbers of radiographs were used), possibly contributing to detection bias. Second, the inclusion and exclusion criteria and ascertainment methods varied across studies. For example, the study by Lucas-Herald and colleagues included only infants born at $<37$ weeks gestation with rib fractures, ${ }^{32}$ whereas the study by Strouse and Owings included all children $<48$ months old with rib fractures. ${ }^{29}$ Third, there was variability in the method of assessing for child abuse across studies, evidenced by lower rates of abusive injury in studies with stricter criteria for determining abuse. An example of this situation is in the study by Bulloch and colleagues: when cases of likely or probable abuse were excluded, the abuse prevalence decreased from 
$82.1 \%$ to $66.7 \% .{ }^{3}$ Fourth, most studies had small sample sizes, limiting their statistical power to detect differences in characteristics between abusive rib fractures and accidental rib fractures. Moreover, while it would be helpful to know whether the prevalence of abuse changes for young children with 1 or 2 rib fractures compared to those with $>2$ rib fractures, this information is not available in the current literature. Lastly, there is risk for circular reasoning in retrospectively identifying factors associated with the likelihood of abuse, if those same factors influenced the decision to diagnose abuse. It is widely accepted that rib fractures in in young children are highly suspicious for abuse, and this may influence a clinician's decision to diagnose abuse when the cause of injury was not independently witnessed.

This review highlights the need for prospective studies in determining the prevalence of abuse among young children with rib fractures and the characteristics of rib fractures that are associated with abuse. In such studies, there should be standardized selection of cases, uniform clinical evaluation of cases, comprehensive data collection, and rigorous methods for determining abuse. In absence of a gold standard, abuse determination methods should include use of specific case-based criteria as well as abuse confirmed by Child Protective Services (CPS) or court proceedings. In addition, studies need to include enough subjects to have sufficient power to detect differences in demographic and/or clinical characteristics between cases of abusive rib fractures and cases of non-abusive rib fractures. Finally, inclusion of oblique radiographs and follow-up skeletal surveys may increase the sensitivity of detecting rib fractures during clinical evaluation. ${ }^{40-42}$

\section{Supplementary Material}

Refer to Web version on PubMed Central for supplementary material.

\section{Acknowledgments}

Sources of Funding: Dr. Christian provides medical legal expert work in cases of child abuse. This review was funded by grant 1K23HD071967 from the National Institute of Child Health and Human Development grant. Dr. Wood's institution has received payment for court testimony that she has provided in cases of suspected child abuse for which she has been involved in the care of the child and subpoenaed to testify.

\section{Abbreviations}
AAP
American Academy of Pediatrics
CI
confidence interval
CPS
child protective services
MVC
motor vehicle crash
RCT
randomized control trial

\section{References}

1. Flaherty EG, Perez-Rossello JM, Levine MA, Hennrikus WL. Evaluating children with fractures for child physical abuse. Pediatrics. 2014; 133(2):e477-489. [PubMed: 24470642] 
2. Kleinman, PK. Bony thoracic trauma. In: Kleinman, PK, editorDiagnostic imaging of child abuse. 2nd. Mosby; St. Louis, Missouri: 1998. 110-148.

3. Bulloch B, Schubert CJ, Brophy PD, Johnson N, Reed MH, Shapiro RA. Cause and clinical characteristics of rib fractures in infants. Pediatrics. 2000; 105(4):E48. [PubMed: 10742369]

4. Cadzow SP, Armstrong KL. Rib fractures in infants: red alert! The clinical features, investigations and child protection outcomes. Journal of Paediatrics and Child Health. 2000; 36(4):322-326. [PubMed: 10940163]

5. Barsness C, Cha E, Bensard D, et al. The positive predictive value of rib fractures as an indicator of nonaccidental trauma in children. Journal of Trauma. 2003; 54:1107-1110. [PubMed: 12813330]

6. Kleinman, PK. The spectrum of non-accidental injuries (child abuse) and its imitators. In: Hodler, J, Zollikofer, C, Schulthess, G, editorsMusculoskeletal diseases 2009-2012. Springer Italia; Milan, Italy: 2009. 227-233.

7. Merten D, Radkowski M, Leonidas J. The abused child: a radiological reappraisal. Radiology. 1983; 146(2):377-381. [PubMed: 6849085]

8. Feldman K, Brewer D. Child abuse, Cardiopulmonary resuscitation, and rib fractures. Pediatrics. 1984; 73(3):339-342. [PubMed: 6701057]

9. Kogutt M, Swischuk L, Fagan C. Patterns of injury and significance of uncommon fractures in the battered child syndrome. American Journal of Roentgenology, Radium Therapy, and Nuclear Medicine. 1974; 121(1):143-149.

10. Thomas P. Rib fractures in infancy. Annales de Radiologie. 1977; 20(1):115-122. [PubMed: 557946]

11. Kleinman PK, Marks SC, Adams VI, Blackbourne BD. Factors affecting visualization of posterior rib fractures in abused infants. American Journal of Roentgenology. 1988; 150(3):635-638. [PubMed: 3257621]

12. Cameron, J, Rae, L. Atlas of the battered child syndrome. Churchill Livingstone; London: 1975. The radiological diagnosis. Differential diagnosis; 20-64.

13. Kleinman PK, Marks SC, Spevak MR, Richmond JM. Fractures of the rib head in abused infants. Radiology. 1992; 185(1):119-123. [PubMed: 1523293]

14. Kleinman PK, Marks SC Jr. Richmond JM, Blackbourne BD. Inflicted skeletal injury: a postmortem radiologic-histopathologic study in 31 infants. American Journal of Roentgenology. 1995; 165(3):647-650. [PubMed: 7645487]

15. Kleinman PK, Marks SC Jr. Nimkin K, Rayder SM, Kessler SC. Rib fractures in 31 abused infants: postmortem radiologic-histopathologic study. Radiology. 1996; 200(3):807-810. [PubMed: 8756936]

16. Block RW, Palusci VJ. Child abuse pediatrics: a new pediatric subspecialty. Journal of Pediatrics. 2006; 148(6):711-712. [PubMed: 16769370]

17. National Association of Children's Hospitals and Related Institutions. Responding to child maltreatment: 2008 survey findings and trends. NACHRI; Alexandria, VA: 2009.

18. National Association of Children's Hospitals and Related Institutions. 2005 survey findings: children's hospitals child abuse services. NACHRI; Alexandra, VA: 2006.

19. Meyer JS, Gunderman R, Coley BD, et al. ACR Appropriateness Criteria((R)) on suspected physical abuse-child. J Am Coll Radiol. 2011; 8(2):87-94. [PubMed: 21292182]

20. Marine MB, Corea D, Steenburg SD, et al. Is the new ACR-SPR practice guideline for addition of oblique views of the ribs to the skeletal survey for child abuse justified? AJR Am J Roentgenol. 2014; 202(4):868-871. [PubMed: 24660718]

21. Diagnostic imaging of child abuse. Pediatrics. 2009; 123(5):1430-1435. [PubMed: 19403511]

22. Leventhal JM, Martin KD, Asnes AG. Incidence of fractures attributable to abuse in young hospitalized children: results from analysis of a United States database. Pediatrics. 2008; 122(3): 599-604. [PubMed: 18762531]

23. Worlock P, Stower M, Barbor P. Patterns of fractures in accidental and non-accidental injury in children: a comparative study. British Medical Journal (Clinical Research Ed.). 1986; 293(6539): 100-102. [PubMed: 3089406] 
24. Leventhal JM, Martin KD, Asnes AG. Fractures and traumatic brain injuries: abuse versus accidents in a US database of hospitalized children. Pediatrics. 2010; 126(1):e104-115. [PubMed: 20530077]

25. Lindberg DM, Berger RP, Reynolds MS, Alwan RM, Harper NS. Yield of skeletal survey by age in children referred to abuse specialists. Journal of Pediatrics. 2014; 164(6):1268-1273. [PubMed: 24630357]

26. Duffy SO, Squires J, Fromkin JB, Berger RP. Use of skeletal surveys to evaluate for physical abuse: analysis of 703 consecutive skeletal surveys. Pediatrics. 2011; 127(1):e47-52. [PubMed: 21149429]

27. Maguire S, Mann MK, Sibert J, Kemp A. Are there patterns of bruising in childhood which are diagnostic or suggestive of abuse? A systematic review. Archives of Disease in Childhood. 2005; 90(2):182-186. [PubMed: 15665178]

28. Simel DL, Samsa GP, Matchar DB. Likelihood ratios with confidence: sample size estimation for diagnostic test studies. J Clin Epidemiol. 1991; 44(8):763-770. [PubMed: 1941027]

29. Strouse PJ, Owings CL. Fractures of the first rib in child abuse. Radiology. 1995; 197(3):763-765. [PubMed: 7480753]

30. Garcia VF, Gotschall CS, Eichelberger MR, Bowman LM. Rib fractures in children: a marker of severe trauma. Journal of Trauma. 1990; 30(6):695-700. [PubMed: 2352299]

31. Leventhal JM, Larson IA, Abdoo D, et al. Are abusive fractures in young children becoming less common? Changes over 24 years. Child Abuse \& Neglect. 2007; 31(3):311-322. [PubMed: 17383725]

32. Lucas-Herald A, Butler S, Mactier H, McDevitt H, Young D, Ahmed SF. Prevalence and characteristics of rib fractures in ex-preterm infants. Pediatrics. 2012; 130(6):1116-1119. [PubMed: 23166339]

33. Darling SE, Done SL, Friedman SD, Feldman KW. Frequency of intrathoracic injuries in children younger than 3 years with rib fractures. Pediatric Radiology. 2014; 44(10):1230-1236. [PubMed: 24771095]

34. Pandya NK, Baldwin K, Wolfgruber H, Christian CW, Drummond DS, Hosalkar HS. Child abuse and orthopaedic injury patterns: analysis at a level I pediatric trauma center. Journal of Pediatric Orthopaedics. 2009; 29(6):618-625. [PubMed: 19700994]

35. Hooft AM, Asnes AG, Livingston N, et al. The Accuracy of ICD Codes: Identifying Physical Abuse in 4 Children's Hospitals. Acad Pediatr. 2015; 15(4):444-450. [PubMed: 26142071]

36. Hooft A, Ronda J, Schaeffer P, Asnes AG, Leventhal JM. Identification of physical abuse cases in hospitalized children: accuracy of International Classification of Diseases codes. J Pediatr. 2013; 162(1):80-85. [PubMed: 22854329]

37. Kemp A, Dunstan F, Harrison S, et al. Patterns of skeletal fractures in child abuse: systematic review. BMJ. 2008; 337:a1518. [PubMed: 18832412]

38. Maguire S, Cowley L, Mann M, Kemp A. What does the recent literature add to the identification and investigation of fractures in child abuse: an overview of review updates 2005-2013. EvidenceBased Child Health. 2013; 8:2044-2057.

39. Melville JD, Lukefahr JL, Clarke EA. First rib fractures in abused infants: a report of three cases. Clin Pediatr (Phila). 2012; 51(5):426-430. [PubMed: 22157420]

40. Hansen KK, Prince JS, Nixon GW. Oblique chest views as a routine part of skeletal surveys performed for possible physical abuse--is this practice worthwhile? Child Abuse \& Neglect. 2008; 32(1):155-159. [PubMed: 18096227]

41. Harper NS, Eddleman S, Lindberg DM. The utility of follow-up skeletal surveys in child abuse. Pediatrics. 2013; 131(3):e672-678. [PubMed: 23400607]

42. Singh R, Squires J, Fromkin JB, Berger RP. Assessing the use of follow-up skeletal surveys in children with suspected physical abuse. Journal of Trauma \& Acute Care Surgery. 2012; 73(4): 972-976. [PubMed: 22902733] 


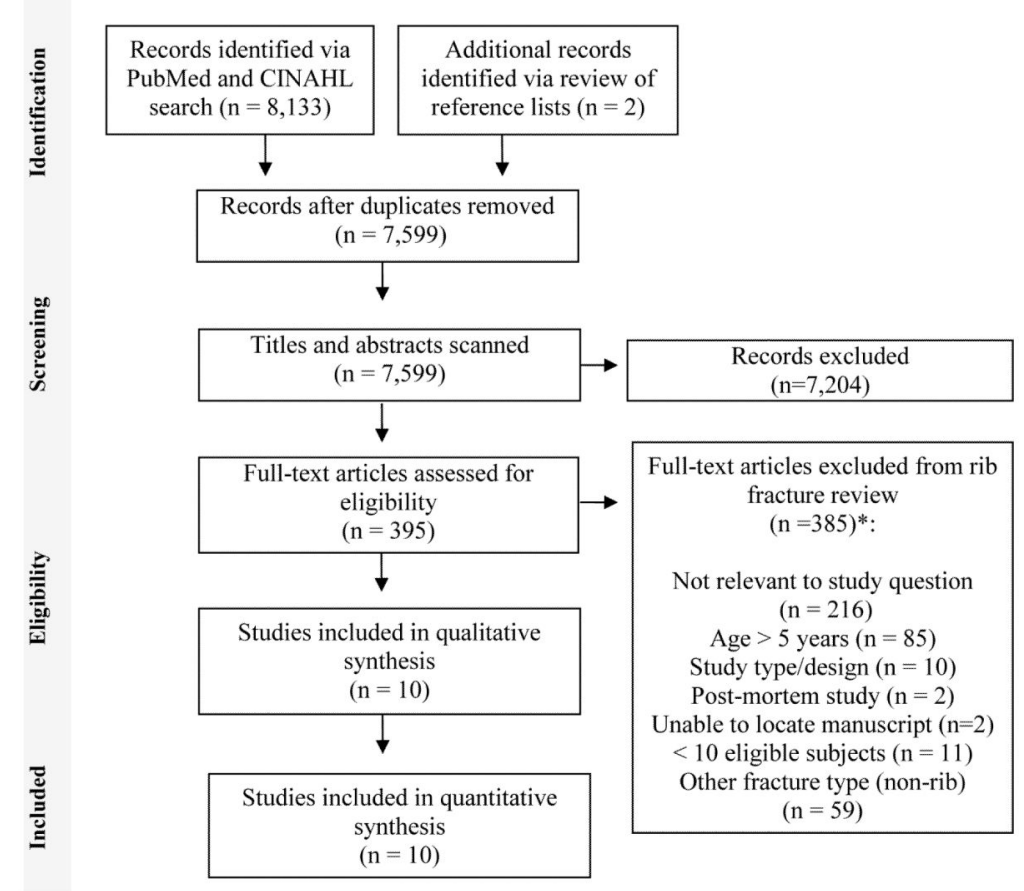

Figure 1. Flow of study identification, screening, eligibility assessment and inclusion *Although some studies could have been excluded for multiple reasons, each study is only listed once in the list of reasons for exclusion. 

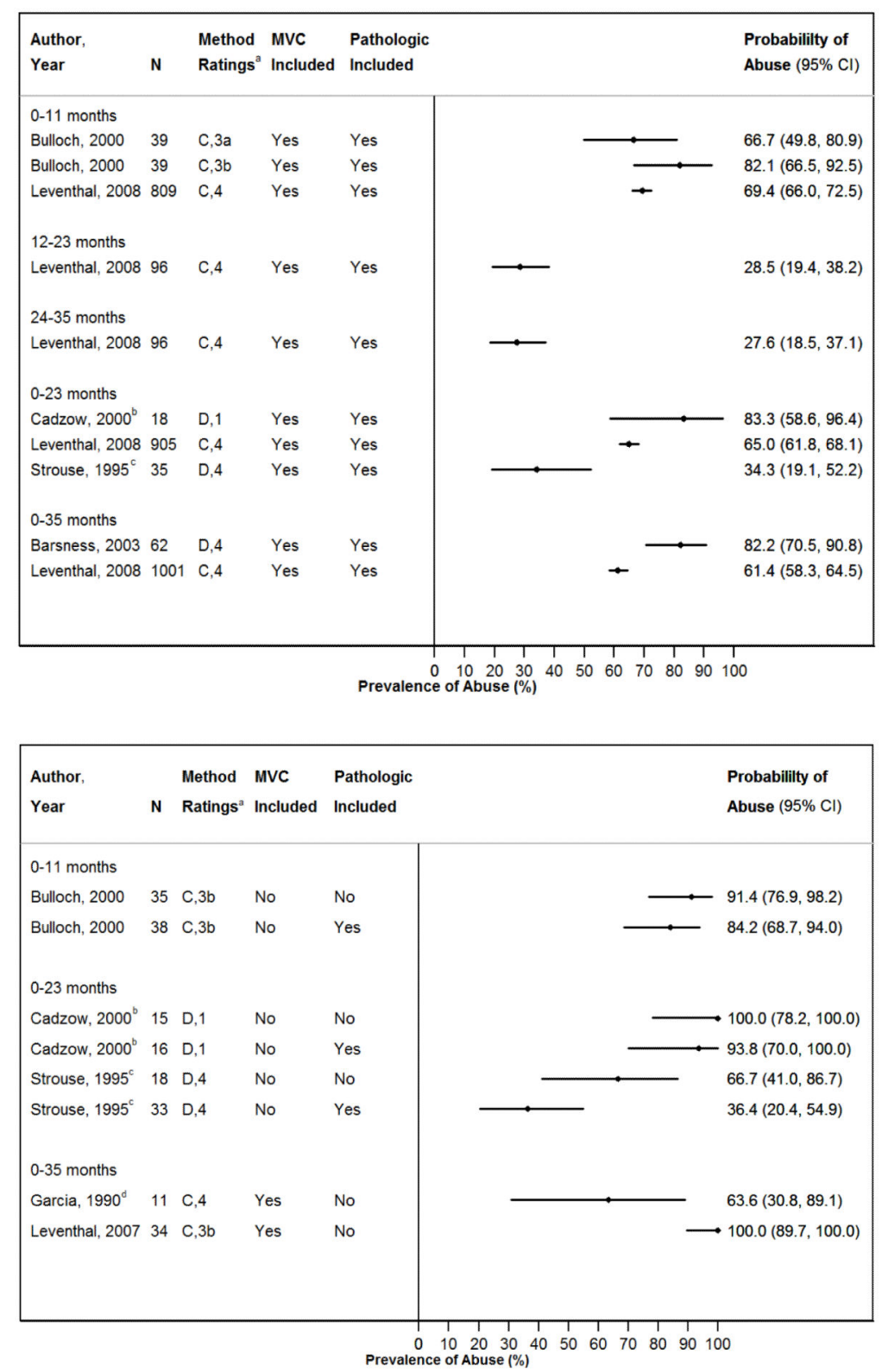

Figure 2. A \& B - Probability of Abuse in Children with Rib Fractures

A. All Children with Rib Fractures (All Etiologies Included)

Proportion of cases with abusive rib fractures in included studies, grouped by subject age.

Ribs fractures caused by MVCs and pathologic diseases were included in the denominator in calculating prevalences.

Abbreviations: $\mathrm{MVC}=$ motor vehicle crash; $\mathrm{n}=$ sample size; $\mathrm{CI}=$ confidence interval.

apresents overall study methodology ranking (A-D) and abuse determination methodology ranking (1-5).

${ }^{b}$ The majority of subjects in this study were $<12$ months old.

'Study inclusion criteria included children up to 4 years old, but all subjects were $0-24$ months old. 


\section{B. Restricted Cohorts Excluding Children with MVC-related Rib Fractures and/or} Pathologic Rib Fractures

Proportion of cases with abusive rib fractures in included studies with restricted cohorts, grouped by subject age.

Abbreviations: $\mathrm{MVC}=$ motor vehicle crash; $\mathrm{n}=$ sample size; $\mathrm{CI}=$ confidence interval.

aPresents overall study methodology ranking (A-D) and abuse determination methodology ranking (1-5).

${ }^{b}$ The majority of subjects in this study were $<12$ months old.

${ }^{\mathrm{c}}$ Study inclusion criteria included children up to 4 years old, but all subjects were 0-24 months old.

${ }^{\mathrm{d}}$ This assumes that all 7 children with rib fractures due to child abuse were $<36$ months old according to the statistics reported. The authors do not report a clear breakdown by age. 


\title{
Table 1
}

\section{Study Methodology Rating Scales}

\author{
General Methodology Rating Scale
}

A Randomized controlled trial (RCT)

B Prospective non-RCT

C Retrospective data analysis with clearly defined sources/criteria

D Retrospective data analysis with unclear sources/criteria

Abuse Determination Methodology Rating Scale ${ }^{a}$

1 Abuse confirmed at case conference or family, civil, or criminal court proceedings; admitted by perpetrator; or witnessed abuse

2 Abuse confirmed by stated criteria including multidisciplinary assessment

3a Abuse defined using specific stated case-based criteria

3b Abuse including cases of likely or probable abuse defined by specific stated case-based criteria

4 Abuse stated but no supporting detail given as to how a determination of abuse was $\operatorname{made}^{b}$

$5 \quad$ Suspected abuse without supporting detail

${ }^{a}$ Adapted from a scale developed by Maguire, et al. ${ }^{28}$ Assessment by multidisciplinary hospital-based child protection team as part of routine clinical care did not qualify as multidisciplinary assessment.

$b_{\text {Includes studies relying on ICD-9 and E-codes for abuse in administrative data sets and studies relying on diagnoses of abuse made by clinical }}$ teams without providing specific criteria by which those diagnoses were made. 
Table 2

Summary of Study Characteristics

\begin{tabular}{|c|c|c|c|c|c|c|c|c|c|}
\hline \multirow[b]{2}{*}{$\begin{array}{l}\text { Study } \\
\left(1^{\text {st }}\right. \\
\text { author, } \\
\text { year })\end{array}$} & \multirow[b]{2}{*}{$\begin{array}{c}\text { Study } \\
\text { Location / } \\
\text { Source }\end{array}$} & \multirow[b]{2}{*}{ Dates } & \multirow[b]{2}{*}{$\begin{array}{l}\text { Age } \\
\text { (mo) }\end{array}$} & \multirow[b]{2}{*}{ Inclusion Criteria } & \multirow[b]{2}{*}{ Exclusions } & \multirow[b]{2}{*}{$N$} & \multicolumn{3}{|c|}{ Study Methods / Bias Assessment } \\
\hline & & & & & & & $\begin{array}{c}\text { Study } \\
\text { Methods } \\
\text { Ranking }^{a}\end{array}$ & $\begin{array}{l}\text { Represent- } \\
\text { ative } \\
\text { population }\end{array}$ & $\begin{array}{c}\text { Clear } \\
\text { selection } \\
\text { criteria }\end{array}$ \\
\hline $\begin{array}{l}\text { Barsness, } \\
2003\end{array}$ & $\begin{array}{c}\text { The } \\
\text { Children's } \\
\text { Hospital, } \\
\text { University } \\
\text { of Colorado } \\
\text { Health } \\
\text { Sciences } \\
\text { Center, } \\
\text { Denver, } \\
\text { CO, USA }\end{array}$ & $\begin{array}{l}6 \text { year } \\
\text { period }\end{array}$ & $<36$ & $\begin{array}{l}\text { Rib fractures all } \\
\text { types }\end{array}$ & None & $62^{c}$ & $\mathrm{D} / 4$ & Yes & No \\
\hline $\begin{array}{l}\text { Bulloch, } \\
2000\end{array}$ & $\begin{array}{c}\text { Children's } \\
\text { Hospital } \\
\text { Medical } \\
\text { Center, } \\
\text { Cincinnati, } \\
\text { Ohio \& } \\
\text { Winnipeg } \\
\text { Children's } \\
\text { Hospital, } \\
\text { Canada }\end{array}$ & 1994-1997 & $<12$ & $\begin{array}{l}\text { Rib fractures all } \\
\text { types }\end{array}$ & None & 39 & $\mathrm{C} / 3 \mathrm{a}$ & Yes & Yes \\
\hline $\begin{array}{l}\text { Cadzow, } \\
2000\end{array}$ & $\begin{array}{c}\text { Royal } \\
\text { Children's } \\
\text { Hospital } \\
\text { Brisbane, } \\
\text { Brisbane, } \\
\text { Australia }\end{array}$ & 1994-1998 & $<24$ & $\begin{array}{l}\text { Rib fractures all } \\
\text { types }\end{array}$ & None & 18 & $\mathrm{D} / 1$ & $\mathrm{No}^{d}$ & No \\
\hline $\begin{array}{l}\text { Darling, } \\
2014\end{array}$ & $\begin{array}{c}\text { Seattle } \\
\text { Children's } \\
\text { Hospital \& } \\
\text { Harborview } \\
\text { Medical } \\
\text { Center, } \\
\text { Seattle, WA, } \\
\text { USA }\end{array}$ & $2003-2010$ & $<36$ & $\begin{array}{l}\text { Rib fractures all } \\
\text { types } \\
\text { attributed to abuse } \\
\text { or } \\
\text { accidental trauma } \\
\& \\
\text { evaluated in ED or } \\
\text { inpatient setting }\end{array}$ & $\begin{array}{l}\text { Determination of } \\
\text { accidental or } \\
\text { abusive etiology } \\
\text { not clearly made, } \\
\text { pathologic fracture }\end{array}$ & 65 & $\mathrm{C} / 3 \mathrm{~b}$ & No & Yes \\
\hline $\begin{array}{l}\text { Garcia, } \\
1990\end{array}$ & $\begin{array}{l}\text { Children's } \\
\text { National } \\
\text { Medical } \\
\text { Center, } \\
\text { Washington, } \\
\text { DC, } \\
\text { USA }\end{array}$ & $1985-1988$ & $<36$ & $\begin{array}{c}\text { Rib fractures all } \\
\text { types } \\
\text { Blunt or } \\
\text { penetrating } \\
\text { trauma }\end{array}$ & None & 11 & $\mathrm{C} / 4$ & No & No \\
\hline $\begin{array}{l}\text { Leventhal, } \\
2007\end{array}$ & $\begin{array}{l}\text { Yale-New } \\
\text { Haven } \\
\text { Children's } \\
\text { Hospital, } \\
\text { CT, USA }\end{array}$ & $\begin{array}{l}1979-1983 \\
1991-1994 \\
1999-2002\end{array}$ & $<36$ & $\begin{array}{l}\text { Rib fractures all } \\
\text { types }\end{array}$ & Pathologic fracture & $34^{c}$ & $\mathrm{C} / 3 \mathrm{~b}$ & Yes & Yes \\
\hline $\begin{array}{l}\text { Leventhal, } \\
2008\end{array}$ & $\begin{array}{l}\text { National } \\
\text { (Kids' } \\
\text { Inpatient } \\
\text { Database, } \\
\text { USA) }\end{array}$ & 2003 & $<36$ & $\begin{array}{l}\text { Rib fractures all } \\
\text { types }\end{array}$ & $\begin{array}{c}\text { Birth related } \\
\text { hospitalization }\end{array}$ & $1001^{c}$ & $\mathrm{C} / 4$ & Yes & Yes \\
\hline $\begin{array}{l}\text { Lucas- } \\
\text { Herald, } \\
2012\end{array}$ & $\begin{array}{l}\text { Three } \\
\text { neonatal } \\
\text { units, } \\
\text { Glasgow, } \\
\text { UK }\end{array}$ & $2000-2010$ & $<12$ & $\begin{array}{c}\text { Born at }<37 \\
\text { weeks } \\
\text { gestational age } \\
\text { Rib fractures all } \\
\text { types }\end{array}$ & $\begin{array}{l}\text { Rib fracture } \\
\text { related } \\
\text { to thoracotomy } \\
\text { surgery }\end{array}$ & $26^{c}$ & $\mathrm{C} / 5$ & No & Yes \\
\hline $\begin{array}{l}\text { Pandya, } \\
2009\end{array}$ & $\begin{array}{l}\text { Children's } \\
\text { Hospital of }\end{array}$ & 1998-2007 & $\leq 48$ & $\begin{array}{l}\text { Rib fractures all } \\
\text { types }\end{array}$ & $\begin{array}{l}\text { Determination of } \\
\text { accidental or }\end{array}$ & 105 & $\mathrm{D} / 4$ & No & No \\
\hline
\end{tabular}




\begin{tabular}{|c|c|c|c|c|c|c|c|c|c|}
\hline \multirow[b]{2}{*}{$\begin{array}{c}\text { Study } \\
\left(1^{\text {st }}\right. \\
\text { author, } \\
\text { year })\end{array}$} & \multirow[b]{2}{*}{$\begin{array}{c}\text { Study } \\
\text { Location / } \\
\text { Source }\end{array}$} & \multirow[b]{2}{*}{ Dates } & \multirow[b]{2}{*}{$\begin{array}{l}\text { Age } \\
(\mathbf{m o})\end{array}$} & \multirow[b]{2}{*}{ Inclusion Criteria } & \multirow[b]{2}{*}{ Exclusions } & \multirow[b]{2}{*}{$N$} & \multicolumn{3}{|c|}{ Study Methods / Bias Assessment } \\
\hline & & & & & & & $\begin{array}{c}\text { Study } \\
\text { Methods } \\
\text { Ranking } a\end{array}$ & $\begin{array}{l}\text { Represent- } \\
\text { ative } \\
\text { population } b\end{array}$ & $\begin{array}{c}\text { Clear } \\
\text { selection } \\
\text { criteria }\end{array}$ \\
\hline & $\begin{array}{l}\text { Philadelphia, } \\
\text { PA, USA }\end{array}$ & & & & $\begin{array}{l}\text { abusive etiology } \\
\text { not clearly made }\end{array}$ & & & & \\
\hline $\begin{array}{l}\text { Strouse, } \\
1995\end{array}$ & $\begin{array}{c}\text { University } \\
\text { of Michigan } \\
\text { Medical } \\
\text { Center, Ann } \\
\text { Arbor, } \\
\text { MI, USA }\end{array}$ & 1992-1994 & $<48$ & $\begin{array}{l}\text { Rib fractures all } \\
\text { types }\end{array}$ & None & 35 & $\mathrm{D} / 4$ & Yes & Yes \\
\hline
\end{tabular}

Abbreviations: mo=months old; $\mathrm{N}=$ sample size; $\mathrm{ED}=$ emergency department.

${ }^{a}$ Presents general study methodology ranking (A-D) and abuse determination methodology ranking (1-5). See Table 1 for description of the ranking scales. Some studies utilized multiple different methods to define cases of abuse or suspected abuse and therefore received more than one ranking.

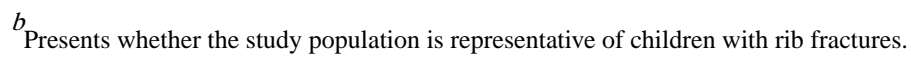

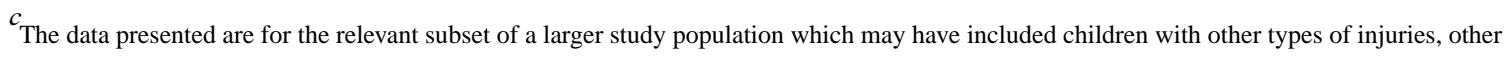
ages, and/or from other time periods.

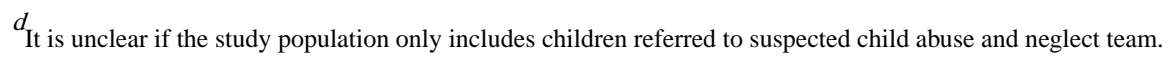


Table 3

Association of Demographic and Rib Fracture Characteristics with Likelihood of Abuse

\begin{tabular}{|c|c|c|c|c|c|c|}
\hline Characteristics & Study & Sensitivity & Specificity & LR+ & LR- & $p^{a}$ \\
\hline \multicolumn{7}{|l|}{ Age (months) } \\
\hline $0-6$ vs. $7-11$ & Darling, 2014 & $90.9 \%(82.4 \%-99.4 \%)$ & $25.0 \%(0.0 \%-67.4 \%)$ & $1.2(0.7-2.2)$ & $0.4(0.1-2.5)$ & 0.366 \\
\hline $0-11$ vs. $12-23$ & Darling, 2014 & $93.6 \%(86.6 \%-100.0 \%)$ & $60.0 \%(29.6 \%-90.4 \%)$ & $2.3(1.1-5.0)$ & $0.1(0.0-0.4)$ & $<0.001$ \\
\hline $0-11$ vs. $12-23$ & Leventhal, 2008 & $95.4 \%(93.7 \%-97.1 \%)$ & $21.8 \%(17.2 \%-26.3 \%)$ & $1.2(1.1-1.3)$ & $0.2(0.1-0.3)$ & $<0.001$ \\
\hline $0-17$ vs. $18-48$ & Pandya, 2009 & $88.3 \%(81.8 \%-94.8 \%)$ & $54.5 \%(25.1 \%-84.0 \%)$ & $1.9(1.0-3.7)$ & $0.2(0.1-0.5)$ & 0.002 \\
\hline $12-23$ vs. $24-35$ & Darling, 2014 & $100 \%$ (NA) & $57.1 \%(\mathrm{NA})$ & $2.3(1.3-4.3)$ & $0(\mathrm{NA})$ & 0.206 \\
\hline \multicolumn{7}{|l|}{ Gender } \\
\hline Male vs. female & Darling, 2014 & $57.4 \%(43.3 \%-71.6 \%)$ & $38.9 \%(16.4 \%-61.4 \%)$ & $0.9(0.6-1.5)$ & $1.1(0.6-2.1)$ & 0.51 \\
\hline \multicolumn{7}{|l|}{ Location } \\
\hline Posterior vs. no posterior & Bulloch, 2000 & $62.5 \%(45.7 \%-79.3 \%)$ & $28.6 \%(0.0 \%-62.0 \%)$ & $0.9(0.5-1.5)$ & $1.3(0.4-4.6)$ & 0.507 \\
\hline $1^{\text {st }}$ rib vs no $1^{\text {st }}$ rib $^{b}$ & Strouse, 1995 & $25.0 \%(0.5 \%-49.5 \%)$ & $95.7 \%(87.3 \%-100.0 \%)$ & $5.8(0.7-49.5)$ & $0.8(0.6-1.1)$ & 0.106 \\
\hline Bilateral vs. unilateral & Darling, 2014 & $42.6 \%(28.4 \%-56.7 \%)$ & $94.4 \%(83.9 \%-100.0 \%)$ & $7.7(1.1-53.0)$ & $0.6(0.5-0.8)$ & 0.006 \\
\hline \multicolumn{7}{|l|}{$\underline{\text { Stages of fractures }}$} \\
\hline Healing vs. no healing & Darling, 2014 & $89.4 \%$ (NA) & $100.0 \%(\mathrm{NA})$ & NA & $0.1(0.0-0.2)$ & $<0.001$ \\
\hline $\begin{array}{l}\text { Multiple vs. single } \\
\text { stages }\end{array}$ & Darling, 2014 & $17.0 \%(\mathrm{NA})$ & $100.0 \%$ (NA) & NA & $0.8(0.7-0.9)$ & 0.062 \\
\hline \multicolumn{7}{|l|}{$\underline{\text { Additional injuries }}$} \\
\hline Present vs. none & Cadzow, 2000 & $80.0 \%$ (NA) & $0.0 \%$ (NA) & $0.8(0.6-1.0)$ & NA & 1.0 \\
\hline Intrathoracic vs. none & Darling, 2014 & $12.8 \%(3.2 \%-22.3 \%)$ & $44.4 \%(21.5 \%-67.4 \%)$ & $0.2(0.1-0.5)$ & $2.0(1.2-3.3)$ & 0.001 \\
\hline \multicolumn{7}{|l|}{$\begin{array}{l}\text { vs. } \\
\text { none }\end{array}$} \\
\hline Intra-abdominal vs. none & Darling, 2014 & $14.9 \%(4.7 \%-25.1 \%)$ & $83.3 \%(66.1 \%-100.0 \%)$ & $0.9(0.3-3.1)$ & $1.0(0.8-1.3)$ & 0.57 \\
\hline Intracranial vs. none & Darling, 2014 & $57.4 \%(43.3 \%-71.6 \%)$ & $61.1 \%(38.6 \%-83.6 \%)$ & $1.5(0.8-2.8)$ & $0.7(0.4-1.1)$ & 0.14 \\
\hline $\begin{array}{l}\text { Retinal hemorrhages vs. } \\
\text { none }\end{array}$ & Darling, 2014 & $36.2 \%(\mathrm{NA})$ & $100.0 \%(\mathrm{NA})$ & NA & $0.6(0.5-0.8)$ & 0.005 \\
\hline $\begin{array}{l}\text { Extrathoracic fractures } \\
\text { (non-skull) vs. none }\end{array}$ & Darling, 2014 & $70.2 \%(57.1 \%-83.3 \%)$ & $83.3 \%(66.1 \%-100.0 \%)$ & $4.2(1.5-12.0)$ & $0.4(0.2-0.6)$ & $<0.001$ \\
\hline Skull fractures vs. none & Darling, 2014 & $23.4 \%(11.3 \%-35.5 \%)$ & $68.4 \%(47.5 \%-89.3 \%)$ & $0.7(0.3-1.7)$ & $1.1(0.8-1.6)$ & 0.54 \\
\hline
\end{tabular}

Pediatr Emerg Care. Author manuscript; available in PMC 2020 February 01. 